\title{
Molecular Prevalence and Clinical Importance of Torque Teno Virus Infection in Thalassemia Patients as High Risk Individuals
}

\author{
Hassan Zabetian ${ }^{1}$, Reza Sahraei ${ }^{1}$, Hossein Hakimelahi ${ }^{1}$, Alireza Yusefi $^{1 *}$, \\ Mohammad Sadegh Sanie ${ }^{1}$, Saeideh Erfanian ${ }^{1}$, Abdolreza Sotoodeh Jahromi ${ }^{1}$, \\ Abdolali Sepidkar ${ }^{1}$, Abdolhossien Madani ${ }^{2}$, Farshid Kafilzadeh ${ }^{3}$ \\ and Mohammad Kargar ${ }^{3}$
}

\author{
${ }^{1}$ Research Center for Non.communicable Diseases, \\ Jahrom University of Medical Sciences, Jahrom, Iran. \\ ${ }^{2}$ Research Center for Social Determinants in Health Promotion, \\ Hormozgan University of Medical Sciences, Bandarabbas, Iran. \\ ${ }^{3}$ Department of biology, Jahrom Branch, Islamic Azad University, Jahrom, Iran
}

http://dx.doi.org/10.13005/bbra/2080

(Received: 09 April 2016; accepted: 18 May 2016)

\begin{abstract}
Recently a novel DNA virus (Torque Teno Virus (TTV) has been identified in Japan and shown to be associated with elevated aminotransferase s levels after transfusion. However the exact role of TTV in pathogenesis of liver disease is yet to be established. The purpose of this study was to determine the prevalence of TTV in thalassemic patients and its relationship with elevated alanine-aminotransfrase (ALT) and aspartateaminotransfrase (AST). This cross-sectional analysis study was conducted on 452 thallasemic patients. Serums were collected from all of the patients, first ALT and AST levels were determined. Then, after DNA extraction, TTV DNA was amplified and detected using semi-nested PCR, followed by gel electrophoresis. Demographic characteristics and clinical data were collected from each participant for statistical analysis. The findings showed that 160 of $452(35.4 \%)$ samples had TTV DNA detected by PCR. From 160 TTV DNA positive, $98(61.20 \%)$ were female and $62(38.80 \%)$ of them were male $(P=0.549)$. The mean ALT and AST values in TTV positive group were higher than in TTV negative group, and the difference was statistically significant $(p<0.0001)$. The result showed that the prevalence of TTV in thalassemic patients in Jahrom is less than other studies in Iran and the mean ALT and AST values in TTV positive individuals were about 2 times more than in TTV negative individuals.
\end{abstract}

Key words: Transfusion Transmitted Virus (TTV), ALT, AST, Thalassemia, Jahrom

Thalassemia are among the most common genetic disorders of the red blood cells in the world and specially has a wide distribution from Europe to south Asiaํ. Because genetically hemolytic anemia in these patients must be supplied blood products to lifelong blood transfusions ${ }^{2}$. In these cases, frequently blood transfusions are associated with various adverse effects such as

\footnotetext{
* To whom all correspondence should be addressed. E-mail: sotoodehj2002@yahoo.com
}

like iron overload, splenectomy, and risk of transfusion transmitted infections ${ }^{3,4}$. Other complications in thalassemic patients are prone to transfusion-related hepatitis, because transfusionrelated iron overloads and exposure to viruses, which may cause hepatitis ${ }^{5-7}$. The screening of hepatitis agents such as hepatitis B virus (HBV), hepatitis $\mathrm{C}$ virus (HCV) always is performed, however a significant rate of thalassemic patients have increased levels of serum alanine aminotransferase (ALT) unknown origin ${ }^{8}$.

In recent periods, a novel non-enveloped single-stranded DNA virus, transfusion- 
transmitted virus (TTV) which indicated to be associated with non A-G post-transfusion hepatitis ${ }^{9}$. TTV infection occurs in the general population and in patients at risk for parenteral exposure, such as those with thalassemia, hemophilia and liver disease ${ }^{10-12}$. TTV is hepatotropic, and has been indicated that TTV infection is related to increased serum transaminases as $\mathrm{ALT}^{13}$. Therefore coinfection with other hepatitis agents can increased tissue injury ${ }^{14}$. Previous study shown that individuals infected with hepatitis B virus or hepatitis $C$ who are positive for TTV infection had evidence of greater liver damage and higher levels of ALT than those with single $\mathrm{HBV}$ and $\mathrm{HCV}^{15,16}$. In these surveys, all of hepatitis patients who were positive for TTV DNA had relatively higher levels of ALT than those who were negative for TTV DNA. However, relationship between TTV infection and post transfusion hepatitis, acute hepatitis, and chronic liver disease with unknown etiology has also been unclear ${ }^{17}$.

Different studies reported that TTV DNA was detectable in $25 \%-96 \%$ and $50.8 \%-84.9 \%$ of patients with chronic hepatitis of unknown cause ${ }^{13}$, ${ }^{18}$ and common origin $(15,19)$, in $27 \%-69 \%$ of hemophiliacs ${ }^{20,21}$, and in $9.33 \%-18 \%$ of healthy individuals ${ }^{15,22}$. In other reports this rate are demonstrate $64.4 \%$ and $39.4 \%$ in thalassemic patients $^{1,23}$. The prevalence of TTV in hemodialysis patients in different regions of world were $17 \%$, $48.01 \%, 64.8 \%{ }^{22,24,25}$. Also in Jahrom city, the prevalence of TTV in high risk groups such as hemodialysis and blood donors was $27.8 \%$ and $13.4 \%$ respectively ${ }^{26,27}$.

Because the significant prevalence of this virus among thalassemia patients and that thalassemic patients are prone to acquiring TTV infection and also its possibly potential role as a primary cause of post-transfusion hepatitis and increasing the severity of liver disease, we decide investigates the prevalence and clinical importance of TTV infection in multiply transfused thalassemia patients during the study period in Jahrom, southern of Iran.

\section{MATERIALSANDMETHODS}

\section{Study population}

A cross-sectional study was carried out
Coliz unit of Motahhari hospital related to the Jahrom University of Medical Science, Iran, during July from 2012 to December 2013. A total of 452 thalassemic patients were recruited for this study. The standard and primary screening tests, including human immunodeficiency virus (HIV), human T-cell leukemia (HTLV), and hepatitis B (HBV) and C (HCV) were performed in all the study participants and those with any positive result were excluded. Information related to demographic characteristics such as sex, age and splenectomy were collected. Informed consent was obtained from all participants and their parents if the patients were under 18 years of age. The study design was approved by the ethics committee of Jahrom University of Medical Sciences (JUMS).

Serology and Biochemical laboratory tests

Serum ALT and AST levels were measured using an automated analyzer and values higher than 50 and $40 \mathrm{IU} / \mathrm{L}$, respectively, were considered to be abnormal. Anti-HCV, Anti-HIV and Anti-HTLV status was determined by a commercially available Enzyme-linked immunosorbent assay (ELISA) (DIA.PRO, Diagnostic Bioprobes Srl, Italy) according to the manufacturer instructions and hepatitis B surface antigen (HBsAg) was determined by ELISA (A DIA.PRO, Diagnostic Bioprobes Srl, Italy). HCV RNA was detected by RT-PCR as described previously ${ }^{28}$.

Detection of TTV DNA by Semi-Nested-PCR method

About $3 \mathrm{mls}$ of venous blood was collected from each subject. The blood was allowed to clot completely before centrifugation. The DNA genome of TTV was extracted from all serum samples the patients by DNP ${ }^{\mathrm{TM}}$ Kit (CinnaGenIran) according to manufacturer's protocol then were stored at " $20{ }^{æ \%} \mathrm{C}$. Polymerase chain reaction (PCR) was also carried out that the specific primers against to TTV and semi-nested-PCR reaction protocol use as described in previous study ${ }^{29}$.

\section{Statistical tests}

Data were entered and analyzed using SPSS software version 17.1. The Chi-square test or Fisher's exact test was used for categorical variables. Results were reported as the mean \pm standard deviation (SD) for quantitative variables and percentages for qualitative variables. The significant relationships of molecular prevalence of TTV infection in thalassemic patients with 
probable studied risk factors were analyzed by use of t-test. Statistical significance was at the $\mathrm{P} \leq 0.05$ level.

\section{RESULTS}

The patient characterizes are shown in Table 1 . The mean age of the patients was $6.7 \pm 0.8$ years (range 1-44 years). Females comprised the majority (59.1\%) and most of the patients were between 2-4 years (51.1\%). This distribu-tion reflects the current diversity in our population. Maximum serum levels ALT and AST of enrolled subjects were 277 IU/L and 143 IU/L respectively. Our finding shows that TTV-DNA was detected in 160 (35.4\%) of patients. Table 1 shows the prevalence of TTV-DNA in the serum samples. The analysis of PCR products revealed a 271 bp fragment (Figure 1).

Table 2 indicated the demographic and some clinical data for the TTV-positive and TTVnegative thalassemia patients. Seventy-five percent of TTV patients were male and also 67.5\% of TTV-positive thalassemia patients have not Splenectomy. There was not a significant difference in gender and splenectomy between the TTVpositive thalassemia patients and TTV-negative patients $(\mathrm{P}>0.05)$. The mean age of TTV-positive patients was higher than TTV-negative patients that this difference was statistically significant.
The distribution of TTV infection based on age different groups in thalassemia patients in between 2-4 years age was higher than other groups that this different was statistically significant. In patients who were positive for TTV infection had higher levels of ALT and AST than TTV-negative patients. Also positive correlation was seen between ALT serum levels with the prevalence of TTV infection that was a significant correlation $(\mathrm{r}=+0.45 \mathrm{P}<0.0001)$. Of course there are same

Table 1. Demographic and clinical data for the 452 thalassemia patients

\begin{tabular}{lccc}
\hline Variables & $\mathrm{N}$ & $\%$ & Mean \pm SD \\
\hline Age groups & & & $6.7 \pm 0.8$ \\
$\leq 2$ & 92 & 20.4 & \\
$2-4$ & 231 & 51.1 & \\
$4-6$ & 32 & 7.1 & \\
$6-8$ & 15 & 3.3 & \\
e”8 & 82 & 18.1 & \\
Gender & & & \\
Male & 185 & 40.9 & \\
Female & 267 & 59.1 & \\
Splenectomy & & & \\
Yes & 169 & 37.9 & \\
No & 238 & 62.1 & \\
ALT (IU/L) & & & $34.5 \pm 3.3$ \\
AST (IU/L) & & & $33.1 \pm 2.8$ \\
TTV-DNAPositive & 160 & 35.4 & \\
Negative & 292 & 64.6 & \\
& & &
\end{tabular}

Table 2. Comparison of the mean plasma levels of ALT, AST and demographic and clinical data between two groups patients with and without TTV infection

\begin{tabular}{|c|c|c|c|c|}
\hline $\begin{array}{l}\text { Demographic } \\
\text { \& baseline characteristics }\end{array}$ & $\begin{array}{l}\text { TTV positive } \\
\text { N (\%) }\end{array}$ & $\begin{array}{l}\text { TTV negative } \\
\text { N (\%) }\end{array}$ & $\begin{array}{l}\text { Total } \\
\text { N (\%) }\end{array}$ & P-value \\
\hline Gender & & & & 0.5 \\
\hline Male & 62 (38.8\%) & 123 (78.7\%) & 185 & \\
\hline Female & $98(61.2 \%)$ & 169 (79.3\%) & 267 & \\
\hline Age groups (Years) & $3.6 \pm 0.38$ & $1 \pm 1.2$ & & 0.0001 \\
\hline$\leq 2$ & 38 (23.8%) & 54 (58.9\%) & 92 & \\
\hline $2-4$ & $106(66.2 \%)$ & $125(54.1 \%)$ & 231 & \\
\hline $4-6$ & $6(3.8 \%)$ & 26 (81.2\%) & 32 & \\
\hline $6-8$ & $3(1.9 \%)$ & $12(80 \%)$ & 15 & \\
\hline$\geq 8$ & & $7(4.4 \%)$ & 75 (91.5\%) & 82 \\
\hline Splenectomy & & & & 0.13 \\
\hline Yes & 52 (32.5\%) & 117 (40.6\%) & 169 & \\
\hline No & & $108(67.5 \%)$ & $130(44.5 \%)$ & 238 \\
\hline ALT(IU/L) & $49.6 \pm 3.2$ & $25.9 \pm 3$ & & $\leq 0.0001$ \\
\hline AST(IU/L) & $45.2 \pm 3.1$ & $26.8 \pm 2.4$ & & $\leq 0.0001$ \\
\hline
\end{tabular}


correlation between AST serum levels with the prevalence of TTV infection that was statistically significant $(\mathrm{r}=+0.38 \mathrm{P}<0.0001)$.

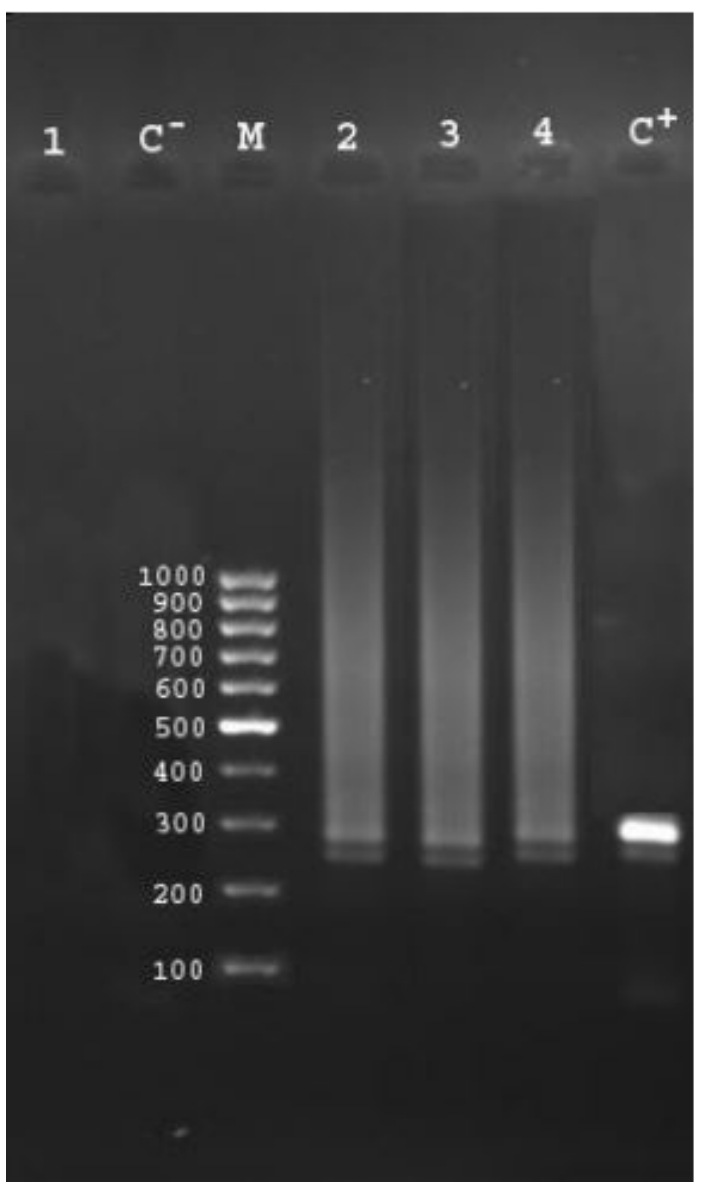

Fig. 1. Identification of TTV by semi nested PCR amplification. From left to right: $1=$ Negative sample,

C- = Negative control, $\mathrm{M}=100 \mathrm{bp}$ DNA Ladder

(Fermentas, Germany), 2, 3, 4= Positive samples, $\mathrm{C}+=$ Positive control respectively. The PCR products size was $271 \mathrm{bp}$.

\section{DISCUSSION}

The use of blood products by thalassemic patients may not always screened therefore infected they receive infectious transmissible agents. These patients may receive repeated transfusions in per month that this condition is able to directly transfer the risk of TransfusionTransmitted Diseases (TTDs) such as microbial and viral infections ${ }^{30}$. Torque teno virus is observed in almost all the tissues and body fluids therefore the possibility of its transmission is high. Furthermore, the potential role and clinical importance of TTV infection in transfusiondependent diseases such as hepatitis in thalassemic patients and other disease, has been important but yet to be established ${ }^{17,31}$. Also subsequent studies raised evidences about the hypothesis that TTV infection leads to clinical manifestation in all infected patients ${ }^{32}$.

In the present study, the prevalence of TTV-DNA was $35.4 \%$ polytransfused thalassemic Iranian patients. The prevalence of TTV varies among thalassemic patients from different regions that this difference in rate of infection is due to differences in diagnostic techniques, study sample size, and geographic distribution ${ }^{33}$. In previous surveys, $50.5 \%$ and $64.4 \%$ patients were TTV-DNA positive $^{1,17}$. Similarly, TTV infection was found to be highly prevalent $63.1 \%-73.4 \%$ in the $\beta$ thalassemic child and adult patients ${ }^{32,34}$. This rate of TTV infection was lower than upper studies. These results with previous studies, suggest that TTV-DNA may has been transmitted in the recipients by blood and blood products. So, blood transfusion is one of the most way for the transmission of TTV in our study.on other hand, However, the fact that High level of TTV is also detected in healthy population with no history of blood transfusion suggests that it can be transmitted not only via blood and injection, but also by other ways ${ }^{35}$. On other hand this could also reflect the greater importance of the parenteral route for virus transmission that has been noted in our study.

In this study, gender and splenectomy did not differ significantly between the present study's TTV-positive and TTV-negative thalassemia patients but age in between two groups was significant. Indeed the prevalence of TTV infection in thalassemic patients based on other variables such as age is important because these patients need to frequent transfusion a long time. In this study the rates of TTV infection in 2-4 years was higher other groups. For example, the rate of TTV infection was increase with age such as $57 \%$ in individuals older than 50 years $^{36}$. The infection may occur at a particular age group and the rates of prevalence of TTV differ among age whereas little children were infected by TTV in two age groups that the age of these patients was from 2- 
40 years $^{37}$. Other survey in Tehran and Ahwaz (a province in southern Iran) showed that there was a significant correlation between TTV infection and age $^{38}$. Our findings indicate the infection rate of TTV increase in particular age that similar to other study $^{38,39}$

In our study, increased levels of ALT and AST were observed in a significant proportion of $\mathrm{TTV}+$ patients and in negative-TTV patients. The reason for this is not clear but might be explained by liver disease associated with transfusion-related iron overload, the presence of undetectable TTV genotypes, or other blood-borne agents. This result was in accordant with previous studies $(32,40)$. On other hand, non significant raised liver enzymes in co-infection with TTV with hepatitis agents such as HCV in thalassemic patients does not alter the plasma level of biochemical markers when compared with TTV infection alone and also for $\mathrm{TTV}+\mathrm{HCV}+$ patients compared with those infected with HCV alone (40). Therefore evaluating the severity of liver disease solely by measurements of plasma transaminase levels is inadequate. Regardless of whether TTV is a cause of liver disease in thalassemic patients, pathogenic mechanisms of the virus need to be rapidly elucidated in order to develop new strategies to prevent transmission and for therapeutic intervention. On the basis of our study, it can be concluded that TTV appears to have a negligible role in increasing the severity of liver disease Thus; we plan to design studies in the future to assess the clinical importance and features of TTV in thalassemia patients.

In conclusion this study has demonstrated that TTV was high in thalasemic patients, which, strongly suggest that blood transfusion may be an important route for TTV transmission. Also, our data support the important role that the parentral route of transfusion plays in the spread of TTV infection. In addition to, our data indicated the effect of TTV infection on severity of liver using increased liver enzymes in between TTV+ patients and in negativeTTV patients.

\section{ACKNOWLEDGEMENTS}

This work was financially supported by a grant from Jahrom University of Medical Sciences. Conflict of interest

\section{REFERENCES}

1. Mansouritorghabeh H, Badiei Z. Transfusiontransmitted viruses in individuals with â thalassemia major at Northeastern Iran, a retrospective sero-epidemiological survey. Iranian Journal of Blood \& Cancer. 2008;1(1):14.

2. Kazazian $\mathrm{Jr} \mathrm{H}$, editor. The thalassemia syndromes: molecular basis and prenatal diagnosis in 1990. Seminars in hematology; 1990.

3. Cunningham MJ, Macklin EA, Neufeld EJ, Cohen AR, Network TCR. Complications of $\beta$ thalassemia major in North America. Blood. 2004;104(1):34-9.

4. Al-Khabori M, Bhandari S, Al-Rasadi K, Mevada S, Al-Dhuhli H, Al-Kemyani N, et al. Correlation of Iron Overload and Glomerular Filtration Rate Estimated by Cystatin C in Patients with $\beta$ Thalassemia Major. Hemoglobin. 2014; 38(5): 365-8.

5. Borgna Pignatti C, Cappellini M, Stefano P, Vecchio G, Forni G, Gamberini M, et al. Survival and complications in thalassemia. Annals of the New York Academy of Sciences. 2005; 1054(1): 40-7.

6. Malik S, Syed S, Ahmed N. Complications in transfusion-dependent patients of B-thalassemia major. Pak J Med Sci. 2009; 25(4):678-82.

7. Jahromi AS, Ahmadi-vasmehjani A, Zabetian H, Hakimelahi H, Yusefi A, Sanie MS, et al. SeroEpidemiological Study of Hepatitis E Virus among Thalassemia as High Risk Patients: A Cross-Sectional Survey in Jahrom, Southern, Iran. Global Journal of Health Science. 2016; 8(9):245.

8. Okamoto H, Mayumi M. TT virus: virological and genomic characteristics and disease associations. Journal of gastroenterology. 2001; 36(8):519-29.

9. Hino S. TTV, a new human virus with single stranded circular DNA genome. Reviews in medical virology. 2002;12(3): 151-8.

10. Poovorawan Y, Tangkijvanich P, Theamboonlers A, Hirsch P. Transfusion transmissible virus TTV and its putative role in the etiology of liver disease. Hepato-gastroenterology. 2000; 48(37): 256-60.

11. Ataei B, Emami Naeini A, Khorvash F, Yazdani MR, Javadi A-A. Prevalence of transfusion transmitted virus infection in hemodialysis patients and injection drug users compared to healthy blood donors in Isfahan, Iran. Gastroenterology research and practice. 2012; 2012. 
12. Peng J, Fang Y, Zhao X, Peng Y. New prevalence estimate of Torque Teno virus (TTV) infection in healthy population and patients with chronic viral hepatitis in Jiujiang, China. Virologica Sinica. 2015; 1-3.

13. Okamoto H, Nishizawa T, Kato N, Ukita M, Ikeda $\mathrm{H}$, Iizuka $\mathrm{H}$, et al. Molecular cloning and characterization of a novel DNA virus (TTV) associated with posttransfusion hepatitis of unknown etiology. Hepatology research. 1998; 10(1): 1-16.

14. García-Álvarez M, Berenguer J, Álvarez E, Guzmán-Fulgencio M, Cosín J, Miralles P, et al. Association of torque teno virus (TTV) and torque teno mini virus (TTMV) with liver disease among patients coinfected with human immunodeficiency virus and hepatitis $C$ virus. European journal of clinical microbiology \& infectious diseases. 2013; 32(2): 289-97.

15. Mousavi-Nasab S, Baharlou R, Ghaderi M, Doosti M, Hashemi S, Samie A, et al. Molecular Epidemiology of Torque Teno Virus (TTV) Isolated from in Healthy and Subjects with Chronic Hepatitis B and C in Jahrom City of Iran. Iranian Journal of Virology. 2013; 7(1):4450 .

16. Zaki M, El Hady NA. Molecular detection of transfusion transmitted virus coinfection with some hepatotropic viruses. Archives of Pathology and Laboratory Medicine. 2006; 130(11):1680.

17. Alavi S, Sharifi Z, Kord Valeshabad A, Nourbakhsh K, Shamsian BS, Arzanian MT, et al. Clinical outcomes of Torque teno virusinfected thalassemic patients with and without hepatitis $C$ virus infection. The Korean journal of hematology. 2011;46(2):123-7.

18. Béland K, Dore-Nguyen M, Gagné M-J, Patey $\mathrm{N}$, Brassard J, Alvarez F, et al. Torque teno virus in children who underwent orthotopic liver transplantation: new insights about a common pathogen. Journal of Infectious Diseases. 2014; 209(2): 247-54.

19. AbuOdeh R, Al Mawlawi N, Al Qahtani AA, Bohol MFF, Al Ahdal MN, Hasan HA, et al. Detection and genotyping of torque teno virus (TTV) in healthy blood donors and patients infected with HBV or HCV in Qatar. Journal of medical virology. 2015;87(7):1184-91.

20. Chen BP, Rumi MG, Colombo M, Lin Y-H, Ramaswamy L, Luna J, et al. TT virus is present in a high frequency of Italian hemophilic patients transfused with plasma-derived clotting factor concentrates. Blood. 1999; 94(12): 4333-6.

21. Simmonds P. Detection of a novel DNA Virus (TTV) in blood donors and blood products (vol
352, pg 191, 1998). Lancet. 1998; 352(9137): 1394-.

22. Afkari R, Pirouzi A, Mohsenzadeh M, Azadi M, Jafari M. Molecular detection of TT virus and SEN virus infections in hemodialysed patients and blood donors in south of Iran. Indian Journal of Pathology and Microbiology. 2012; 55(4): 478.

23. Gomma H. Transfusion transmitted virus (TTV) infection in polytransfused Egyptian thalassemic children. J Med Sci. 2006; 6(5): 8337.

24. Abou-Donia HA, Selim HS, El-Koraei AF, Noha AAG, Kabbary M. TT Virus DNA Among Hemodialysis Patients in Alexandria. Egyptian Journal of Medical Microbiology. 2007;16(1).

25. Takemoto AY, Okubo P, Saito PK, Yamakawa $\mathrm{RH}$, Watanabe MAE, Veríssimo da Silva Junior $\mathrm{W}$, et al. Torque teno virus among dialysis and renal-transplant patients. Brazilian Journal of Microbiology. 2015; 46(1): 307-11.

26. Jahromi AS ES, Farjam MR, Madani A. Molecular epidemiology and clinical importance of TT virus infection in Haemodialysis Patients, South of Iran. Life Sci J 2014;11(2):182-185.

27. Sara A, Solhjoo K, Jahromi ARS, Yaghobi R. Study the prevalence of TT virus infection in South Iranian volunteer blood donors. African Journal of Microbiology Research. 2012; 6(32): 6230-4.

28. Ashrafi Hafez A BR, Mousavi Nasab SD, Ahmadi Vasmehjani A, Shayestehpour M, Joharinia N, et al. . Molecular epidemiology of different hepatitis $\mathrm{C}$ genotypes in serum and peripheral blood mononuclear cells in Jahrom city of Iran. Hepat Mon; 14: e16391. 2014.

29. Koohi AK, Ravanshad M, Rasouli M, Falahi S, Baghban A. Phylogenetic Analysis of Torque Teno Virus in Hepatitis C Virus Infected Patients in Shiraz. Hepatitis monthly. 2012;12(7):437.

30. Jain R, Perkins J, Johnson ST, Desai P, Khatri A, Chudgar U, et al. A prospective study for prevalence and/or development of transfusiontransmitted infections in multiply transfused thalassemia major patients. Asian journal of transfusion science. 2012; 6(2):151.

31. Blejer J, Salamone H. [Is TT virus (TTV) a true hepatitis virus cause?]. Medicina. 1999; 60(5 Pt 1): 631-8.

32. Özyürek E, Ergünay K, Kuskonmaz B, Ünal S, Çetin M, Ustaçelebi S, et al. Transfusiontransmitted virus prevalance in Turkish patients with thalassemia. Pediatric hematology and oncology. 2006; 23(4): 347-53.

33. Kondili LA, Pisani G, Beneduce F, Morace G, Gentili G, Ballati G, et al. Prevalence of TT virus 
in healthy children and thalassemic pediatric and young adult patients. Journal of pediatric gastroenterology and nutrition. 2001; 33(5):62932.

34. Sampietro M, Tavazzi D, Di Montemuros FM, Cerino M, Zatelli S, Lunghi G, et al. TT virus infection in adult beta-thalassemia major patients. Haematologica. 2001; 86(1): 39-43.

35. Okamoto H, Nishizawa T, Takahashi M, Asabe S, Tsuda F, Yoshikawa A. Heterogeneous distribution of TT virus of distinct genotypes in multiple tissues from infected humans. Virology. 2001; 288(2): 358-68.

36. Saback FL, Gomes SA, de Paula VS, da Silva RR, Lewis-Ximenez LL, Niel C. Age-specific prevalence and transmission of TT virus. Journal of medical virology. 1999; 59(3): 318-22.
37. Saláková M, Nìmeèek V, König J, Tachezy R. Age-specific prevalence, transmission and phylogeny of TT virus in the Czech Republic. BMC infectious diseases. 2004; 4(1):56.

38. Zandieh T, Babaahmadi B, Pourfathollah A, Galedari H, Emam J, Jalalifar M. Transfusion Transmitted Virus(TTV) Infection in Thalassemic Patients. Iranian Journal of Public Health. 2005; 34(4): 24-9.

39. Rivanera D, Lozzi M, Idili C, Lilli D. Prevalence of TT virus infection in Italian-dialysis patients. Pathologie Biologie. 2009;57(1):97-100.

40. Hu YW, AlMoslih MI, Al Ali MT, Uzicanin S, Perkins H, Yi QL, et al. Clinical outcome of frequent exposure to Torque Teno virus (TTV) through blood transfusion in thalassemia patients with or without hepatitis $\mathrm{C}$ virus (HCV) infection. Journal of medical virology. 2008; 80(2): 365-71. 